\title{
Review Article \\ Children's Oral Health: The Opportunity for Improvement Using the WHO Health Promoting School Model
}

\author{
Andrew J. Macnab ${ }^{1,2}$ \\ ${ }^{1}$ Department of Pediatrics, University of British Columbia, Room C323, 4500 Oak Street, Vancouver, BC, Canada V6H 3N1 \\ ${ }^{2}$ Stellenbosch Institute for Advanced Study, Wallenberg Research Centre, 10 Marais Street, 7600 Stellenbosch, South Africa \\ Correspondence should be addressed to Andrew J. Macnab; amacnab@cw.bc.ca
}

Received 5 July 2014; Revised 14 December 2014; Accepted 15 December 2014

Academic Editor: Haiying Chen

Copyright (C) 2015 Andrew J. Macnab. This is an open access article distributed under the Creative Commons Attribution License, which permits unrestricted use, distribution, and reproduction in any medium, provided the original work is properly cited.

\begin{abstract}
The health and quality of life of a large proportion of the world's children are compromised by dental caries and periodontal disease. Those in developing countries and from disadvantaged populations suffer disproportionately from these forms of poor oral health; however, much of the primary disease and secondary pathology is preventable by simple and inexpensive measures that children can readily learn. WHO health promoting schools (HPS) are an established model for addressing public health issues through education of children in a manner that achieves acquisition of knowledge and health practices that promote behaviours that positively impact determinants of health. HPS programs that address poor oral health have achieved improvement in oral health practices and reduction in caries rates among disadvantaged populations of children. WHO has called for more programs to address the "epidemic" of poor oral health worldwide, and the WHO HPS model appears to be a relevant and applicable way forward. Health care professionals and educators who want to improve the health and quality of life of children related to caries and periodontal disease now have an opportunity to collaborate to initiate, deliver, and evaluate community-based HPS interventions using proven concepts, content, and process.
\end{abstract}

\section{Introduction}

Dental caries and periodontal disease have a worldwide impact on the health of children $[1,2]$. The negative effects on their wellbeing, quality of life, and overall health during childhood are well documented [3], and in addition the literature reports the association of chronically compromised oral health and a growing number of significant systemic conditions that manifest later in life. These include adverse pregnancy outcomes, cardiovascular disease, stroke, and diabetes [4-7], hence the relevance to public health intervention, although the causal relationships linking periodontal disease to these conditions have not yet been established $[8,9]$. Importantly children in developing countries and disadvantaged populations in the developed world are known to suffer disproportionately from the burden of caries and periodontal disease [10]. And while the majority of such children lack adequate formal dental care because of multiple factors, including cost and limited access, much of the poor oral health from which they suffer is largely preventable when they have access to simple knowledge and are taught inexpensive health care practices. Although risk factors like poverty, dietary habits, and poor nutrition also contribute, even specific local sociobehavioural and environmental factors that play a role in caries and periodontal disease can be addressed in programs that provide health promotion focussed on improvement of oral health.

Many such programs now exist, but strengthening and increasing their availability has been called for, particularly in developing countries, and amongst disadvantaged special populations [11]. Such calls include ones from the World Health Organization (WHO), and WHO advocates the use of Health Promoting Schools (HPS) as an effective avenue for promoting and protecting health in children $[12,13]$. In addition, WHO defines a health promoting school as one that "constantly strengthens its capacity to as a healthy setting for living, learning and working," recognizing the broader impact where effective HPS programs alter the ethos of the whole school [14]. HPS provide classroom education and school-based activities that increase knowledge and develop 
behaviors that benefit the health of children. Such schools are also an investment in the wellbeing of the larger community, and HPS programs can be targeted to address health issues of particular relevance to a given community. Because children's oral health is one public health issue where improvement has been achieved through HPS programs this paper summarizes the negative impact of poor oral health on children, explains the concept of school-based health promotion using the WHO HPS model, and describes the content incorporated and methods used for evaluation of HPS programs to improve oral health.

\section{Poor Oral Health in Children}

Caries is regarded as the commonest preventable infectious disease affecting children [15], and periodontal diseases are estimated to affect up to $90 \%$ of the world's population [8]. Caries develops when tooth surfaces are damaged by acids produced when bacteria present in the mouth ferment carbohydrates and food debris. The risk factors for caries and periodontal disease are well described [16-18], but in children dietary intake of sugars and carbonated soft drinks combined with poor oral hygiene are important factors that promote an environment conducive to bacterial activity and biofilm (plaque) formation [15]. Gingivitis develops as dental plaque accumulates in proximity to the gingiva. Plaque harbours bacteria such as Streptococcus mutans and causes inflammation of the gingival (gum) margins, which is the first stage of periodontal disease [19]. Periodontitis results in loss of connective tissue and tooth loss. Undernutrition increases a child's susceptibility to dental caries; however, diets common in developing countries that contain predominantly starchy foods, fruits, and vegetables are also linked to low levels of dental caries [20].

Children with poor oral health experience pain and tooth loss which compromise normal eating and negatively impact their nutrition, self-esteem, speech, socialization, quality of life, and school attendance. Worldwide it is estimated that $>51$ million school hours are lost annually from dental-related illness [2, 17, 21-23]. The consequences of established disease also place a considerable economic burden on children's families and society [24], yet caries can be arrested, and the early stages potentially reversed, by employing measures that are inexpensive and simple to teach [18], principally by the maintenance of oral hygiene through regular removal of food deposits and related measures to reduce dental plaque formation and the negative impact of gingivitis $[25,26]$.

Importantly, children's oral health can be improved through school-based intervention programs that are simple and inexpensive to implement and are readily evaluated $[11,18,27,28]$. A significant reduction in caries rates and improvement in quantitative measures such as the decayed, missing, and filled teeth scores have been documented in several child populations including Canadian aboriginal children and rural primary school pupils in Africa [11, 15, 27-30]. Even though oral hygiene measures are long established practices in most cultures [26], it is possible to improve children's oral hygiene through simple additions to their knowledge and learning improved health practices. Importantly, these two elements of health education, knowledge provision, and teaching/reinforcing healthy practices are the components central to the WHO health promoting school model. Also, in the context of the worldwide need for improvement of children's oral health, none of the interventions necessary to achieve positive change are difficult, expensive, or controversial. Even the use of tooth brushes can be replaced by readily available and acceptable local alternatives such as tooth sticks, in situations where even the modest cost of tooth brushing is not financially viable or is not accepted as an intervention, as is the case in some Muslim countries [31].

\section{Health Promoting Schools (HPS)}

The concepts underlying the WHO HPS model for health promotion in schools have been well described previously, as have their history and evolution, initiatives implemented in a range of different countries, and the methods used to document impact and processes that contribute to success or failure [12, 32-38]. And a 2014 structured review evaluated the evidence for improvement of student health and wellbeing and academic achievement [39]. In HPS health education curriculum content is included in classroom teaching and school-based "healthy practice" activities are provided that together increase knowledge and develop and reinforce behaviors that benefit the health of children.

While many schools begin by addressing a single health topic [40] (poor oral health is an example) WHO also advocates for a broader "whole-school" approach where the health and educational outcomes of children and adolescents are enhanced by a broad range of approaches and learning experiences that effectively alter the ethos of the school towards health. HPS activities benefit the individual children in the program but there is also a "trickle-down" effect which benefits siblings and parents, and even the broader community has been shown to benefit through dissemination of new knowledge, changes in attitudes, and adoption of healthier behaviours. Hence, such schools are an investment in the health and future wellbeing of the community as a whole.

The current consensus on implementation strategies and the potential of HPS to achieve behavioural change has been summarized in recent publications [13, 41, 42]. Essential first steps and engagement and implementation components central to effective programs have been identified $[12,13,37$, 43-45]. These include the following:

(i) dialogue to identify the health issue(s) to be addressed-it is important that any issue chosen has "relevance" for the community and its importance "resonates" with those who will deliver the HPS program,

(ii) achievement of "buy in" to the need for health education and of the concepts central to HPS,

(iii) planning of the educational content and health practices to be offered, 
(iv) definition of the roles of teachers and collaborating health professionals/educators/agencies,

(v) agreement on support to be provided for HPS program delivery and the evaluation mechanisms to be used to examine impact and effect,

(vi) Professional development for teachers-this has been shown to aid the process of HPS delivery by improving participation by school staff and sustaining their commitment.

A body of evidence exists on the effect of HPS programs implemented to address a variety of health issues, in various populations and different countries; this has been summarized by Tang et al. [12] and systematically reviewed by Langford et al. [39]. However, as with other approaches to health promotion there is still a call for more comprehensive evaluation and in particularly for long term studies on the duration of behavioural change $[12,13]$. Also it is clear that not only do the children, whole school, and broader community benefit from effective HPS programs, those collaborating to initiate and deliver them also derive benefits from the experience, and many report increased awareness of "real world" challenges and solutions related to public health issues such as the prevalence of poor oral health amongst children [28, 46]. Effective HPS programs can be established in individual schools or local communities and in many countries national agencies exist for HPS-based health promotion [42].

\section{Content and Evaluation of HPS Oral Health Programs}

Factual teaching around oral health is added to classroom curriculum and visual aids are prepared and displayed that highlight key facts and beneficial behaviours. While the children learn the association between caries formation and acid production from sugars in the mouth by bacteria and the importance of oral hygiene to break this cycle, their attention can be drawn to relevant dietary practices $[15,20,46]$. These include the sources of sugar in the diet, especially the addition of sugar to food and drinks, and the high sugar content of carbonated beverages. Candy and chocolate consumption, snacking practices, and less healthy food preferences driven by advertising can also be addressed, and emphasis is placed on the choice of local alternatives that are healthier and available in individual communities. In many developing countries such alternatives include fruit, nuts, and sugar cane. Although cane contains sugar, it is naturally fibrous. Consequently chewing and sucking it cleans teeth and gums effectively, and the cleansing effect outweighs the potential risk of the sugar content as a potential cause of caries [47].

Healthy practices taught in the context of improving oral health include methods to effectively cleanse the mouth and in particular how and when to remove food debris and accumulations of sugars, acids, and forming biofilm [11, 15, 27]. The principal practice in this regard is tooth brushing [ 25 , 46] but in many developing countries will also incorporate the use of tooth sticks as an acceptable alternative. Tooth sticks can be as effective in removing plaque as tooth brushes
[48], and WHO advocates their use in oral health programs. An additional benefit of incorporating their use in HPS programs is that no cost is involved if suitable sticks are harvested locally by participating children, or very low cost if supplies are purchased in village markets. In many countries suitable sticks can be sourced from a variety of local trees and shrubs that have a suitably fibrous structure, and some of these are known containing agents that inhibit the activity of oral bacteria including Streptococcus mutans, the bacteria principally responsible for caries formation [26, 49, 50]. However, regardless of the method used to clean the teeth instruction on what constitutes a good technique must be explained and demonstrated carefully, and conduct of the "healthy practice" must be checked and reinforced in daily oral hygiene sessions that in most schools are instituted after the daily lunch break. In our programs we have found it particularly important to ensure that children are taught to clean their posterior teeth and interdental surfaces effectively [15].

Teaching should also address any local practices that are potentially harmful to the teeth or gums, such as the use of ash as cleaning agents, and where possible suggest healthy alternative measures [46]. Positive practices that can be done at home and shared with siblings and parents should also be addressed. In some communities incentive programs enhance interest and compliance related to desired changes in behaviour. In class quizzes keep knowledge current and maintain focus on oral health as an issue, and health messages disseminated amongst participants using social media are a recent addition to the medium of health promotion $[28,51]$.

An evaluation process should monitor program effectiveness and enable both the curriculum "knowledge" and "healthy practices" content taught to be refined and improved where necessary.

Processes for evaluation depend on the resources available and desired outcome criteria [36, 37, 42]. Examples include surveys, interviews, and self-report questionnaires; such tools can provide numeric data on participation and with the use of open ended questions can provide relevant information on what works and what needs to be improved $[15,39]$. Responses can be content coded or used as qualitative data. For example, when asked what changes children noted in their oral health the commonest response was that their mouths no longer "smelled bad." Though subjective, this observation is valuable as it equates with the reduced incidence of halitosis secondary to gingivitis documented by Quirynen et al. [52]. Other social consequences of poor oral health and evidence of behavioral impact of HPS programs are also captured in this way.

Quantitative indices, and particularly those documenting the effects of caries, are the "gold standard" measures of oral health. An example is the decayed missing filled teeth (DMFT) index [52], an established measure performed according to criteria described by WHO [53], by a health care provider trained to do a standard oral examination. The surfaces of each tooth are examined and the presence or absence of caries is recorded. A tooth is considered as filled where it has permanent restoration and missing due to caries if pain or a cavity was noted prior to extraction [54]. Cohorts 
of children in HPS oral health promotion programs can be evaluated before programs begin and then annually thereafter $[28,39]$. These data are robust validated quantitative measure that allows valid comparisons to be made within and between national cohorts and even with international data sets [15]. However, DMFT and comparable quantitative scores do require trained personal to conduct them and provision of examination gloves and disposable dental instruments; therefore a significant cost is involved that may be beyond the scope of some intervention programs. While all HPS oral health initiatives should have some element of evaluation to ensure the relevance of the program and enable modifications to be made, it can be argued that the evidence for the basic interventions that improve oral health is sufficiently validated and robust that where necessary quantitative measures at the level of DMFT are not always warranted in a school-based program.

\section{Conclusions}

Poor oral health is an example of a worldwide public health issue of central importance for children, with caries being both the commonest childhood infectious disease and the most common preventable cause of chronic inflammation. As a consequence of caries, gingivitis, periodontal disease, and tooth loss millions of children worldwide experience significant morbidity and impairment of their quality of life. However, the majority of the poor oral health they experience can be prevented altogether or significantly improved through changes in behaviour achieved by teaching them a combination of simple factual knowledge and inexpensive healthy practices. And these two basic elements of health promotion are known to be provided through use of the WHO HPS model. In the context of oral health HPS programs have been shown to increase knowledge, reduce the self-reported incidence of halitosis, improve oral hygiene practices, change dietary preferences and increase healthy eating, decrease independently documented rates of caries, and result in improved DMFT scores [11, 15, 27-30, 39, 46].

Health care providers, those involved in public health research, and governments have a significant role to play in the ongoing transformation of health knowledge and behaviours $[55,56]$, and the WHO HPS model is a validated method for them to initiate collaborative community-based intervention to address a locally relevant health issue. As recent innovative approaches show, where such individuals enter into partnership with policy makers and engage in knowledge exchange with advocacy groups and professionals such as teachers, mutual benefits result that lead to more effective interventions to address the health needs prevalent in communities. Such benefits accrue because collaboration brings together different perspectives and competencies that optimize use of available expertise and elevate understanding of innovative approaches [57]. For those looking to initiate health promotion in schools poor oral health is an ideal starting point as it is a topic with no stigma or cultural or religious overtones, which has relevance to almost every population [40]. A possible exception would be communities where naturally high fluoride levels in the water result in a much lower incidence of caries than usual.

HPS programs initiated to address a variety of issues have been documented to result in children acquiring knowledge and practical skills that enable them to positively impact key determents of health $[12,39]$. Such children are more likely to choose health behaviours and a lifestyle that reduces their susceptibility to preventable diseases. And, importantly, these positive attitudes and behaviours established in childhood and youth are known to contribute beneficially to their behaviours as adults, because the habits of living established in these early years, be they beneficial or negative, significantly impact their choices and how they behave in later life [58]. Today the WHO HPS model is relevant as a means of health promotion as very large numbers of children worldwide experience deficiencies that negatively impact a broad range of health indicators, yet many of these can be addressed through HPS initiatives [55, 59, 60]. Importantly, there is growing evidence of positive benefits evident amongst children in HPS schools and also in the broader community. Also, such improvement can be achieved with modest investment and in developing countries and amongst disadvantaged populations, as initiating HPS activities requires a change in mindset and small additions to the curriculum rather than major investment in resources, training of additional health care professionals, or new infrastructure.

It is relevant in the context of promotion of oral health that HPS initiatives that address prevention of caries and periodontal disease, increase knowledge of healthy dietary choices, and promote healthy practices are some of the simplest and least expensive to initiate. Also that oral health promotion is more affordable than the cost of traditional restorative treatments, a fact with particular relevance in the financial climate of current times [55]. And, as with all HPS programs, children who benefit from effective program delivery can be expected to have less dependence on government funded health care delivery because of the reduction in their predisposition to preventable illness because of the lifestyle changes, knowledge, and practices that they acquire. It is also recognized that improved health in turn promotes more successful learning, probably through both a reduction in school absence due to illness and improved academic performance. And, arguably, because of what is known about the association of poor oral health with predisposition to adult diseases, there is also a health and potential cost benefit, as pregnancy outcomes, the consequences of heart disease and stroke, and growing burden of diabetes are of growing relevance even in the developing world [61, 62]. Thus HPS programs contribute to the best possible use being made of available human, financial, and community resources and hence are of particular relevance as a health intervention in schools in low and middle income countries. And it is for such reasons that the WHO sees HPS programs as a particularly sound investment in global child health.

\section{Conflict of Interests}

The author declares that there is no conflict of interests regarding the publication of this paper. 


\section{References}

[1] P. E. Petersen, D. Bourgeois, D. Bratthall, and H. Ogawa, "Oral health information systems-towards measuring progress in oral health promotion and disease prevention," Bulletin of the World Health Organization, vol. 83, no. 9, pp. 686-693, 2005.

[2] B. Christian and A. S. Blinkhorn, "A review of dental caries in Australian aboriginal children: the health inequalities perspective," Rural and Remote Health, vol. 12, no. 4, article 2032, 2012.

[3] C. McGrath, H. Broder, and M. Wilson-Genderson, "Assessing the impact of oral health on the life quality of children: implications for research and practice," Community Dentistry and Oral Epidemiology, vol. 32, no. 2, pp. 81-85, 2004.

[4] A. J. Grau, H. Becher, C. M. Ziegler et al., "Periodontal disease as a risk factor for ischemic stroke," Stroke, vol. 35, no. 2, pp. 496-501, 2004.

[5] M. Ide and P. N. Papapanou, "Epidemiology of association between maternal periodontal disease and adverse pregnancy outcomes - Systematic review," Journal of Clinical Periodontology, vol. 40, no. 14, supplement, pp. S181-S194, 2013.

[6] J. J. Taylor, P. M. Preshaw, and E. Lalla, "A review of the evidence for pathogenic mechanisms that may link periodontitis and diabetes," Journal of Periodontology, vol. 40, supplement 14, pp. S113-S134, 2013.

[7] L. L. Humphrey, R. Fu, D. I. Buckley, M. Freeman, and M. Helfand, "Periodontal disease and coronary heart disease incidence: a systematic review and meta-analysis," Journal of General Internal Medicine, vol. 23, no. 12, pp. 2079-2086, 2008.

[8] B. L. Pihlstrom, B. S. Michalowicz, and N. W. Johnson, "Periodontal diseases," The Lancet, vol. 366, no. 9499, pp. 1809-1820, 2005.

[9] P. B. Lockhart, A. F. Bolger, P. N. Papapanou et al., "Periodontal disease and atherosclerotic vascular disease: does the evidence support an independent association?: a scientific statement from the American heart association," Circulation, vol. 125, no. 20, pp. 2520-2544, 2012.

[10] O. Ibiyemi, J. O. Taiwo, and G. A. Oke, "Dental education in the rural community: a Nigerian experience," Rural and Remote Health, vol. 13, no. 2, p. 2241, 2013.

[11] S. Y. L. Kwan, P. E. Petersen, C. M. Pine, and A. Borutta, "Healthpromoting schools: an opportunity for oral health promotion," Bulletin of the World Health Organization, vol. 83, no. 9, pp. 677$685,2005$.

[12] K.-C. Tang, D. Nutbeam, C. Aldinger et al., "Schools for health, education and development: a call for action," Health Promotion International, vol. 24, no. 1, pp. 68-77, 2009.

[13] A. Macnab, "The stellenbosch consensus statement on health promoting schools," Global Health Promotion, vol. 20, no. 1, pp. 78-81, 2013.

[14] World Health Organization, "What is a Health Promoting School?” 2013, http://who.int/school_youth_health/gshi/hps/ en/.

[15] A. Kizito, C. Meredith, Y. Wang, A. Kasangaki, and A. J. Macnab, "Oral health promotion in schools: rationale and evaluation," Health Education, vol. 114, no. 4, pp. 293-303, 2014.

[16] R. C. Page and H. E. Schroeder, "Pathogenesis of inflammatory periodontal disease: a summary of current work," Laboratory Investigation, vol. 34, no. 3, pp. 235-249, 1976.

[17] M. Anderson, "Risk assessment and epidemiology of dental caries: review of the literature," Pediatric Dentistry, vol. 24, no. 5, pp. 377-385, 2002.
[18] R. H. Selwitz, A. I. Ismail, and N. B. Pitts, "Dental caries," The Lancet, vol. 369, no. 9555, pp. 51-59, 2007.

[19] G. C. Armitage, "Periodontal diagnoses and classification of periodontal diseases," Periodontology 2000, vol. 34, pp. 9-21, 2004.

[20] P. J. Moynihan, "The role of diet and nutrition in the etiology and prevention of oral diseases," Bulletin of the World Health Organization, vol. 83, no. 9, pp. 694-699, 2005.

[21] A. Pau, S. S. Khan, M. G. Babar, and R. Croucher, "Dental pain and care-seeking in 11-14-yr-old adolescents in a low-income country," European Journal of Oral Sciences, vol. 116, no. 5, pp. 451-457, 2008.

[22] P. E. Petersen, "Global policy for improvement of oral health in the 21st century-implications to oral health research of World Health Assembly 2007, World Health Organization," Community Dentistry and Oral Epidemiology, vol. 37, no. 1, pp. $1-8,2009$.

[23] A. Rowan-Legg, "Oral health care for children-a call for action," Paediatrics and Child Health, vol. 18, no. 1, pp. 37-43, 2013.

[24] G. Tsakos and C. Quiñonez, "A sober look at the links between oral and general health," Journal of Epidemiology \& Community Health, vol. 67, no. 5, pp. 381-382, 2013.

[25] H. Löe, "Oral hygiene in the prevention of caries and periodontal disease," International Dental Journal, vol. 50, no. 3, pp. 129$139,2000$.

[26] C. D. Wu, I. A. Darout, and N. Skaug, "Chewing sticks: timeless natural toothbrushes for oral cleansing," Journal of Periodontal Research, vol. 36, no. 5, pp. 275-284, 2001.

[27] R. Harrison, D. Duffy, D. Benton, and A. J. Macnab, "Brighter smiles: service learning, inter-professional collaboration and health promotion in a first nations community," Canadian Journal of Public Health, vol. 97, no. 3, pp. 237-240, 2006.

[28] A. J. Macnab, J. Rozmus, D. Benton, and F. A. Gagnon, “3-year results of a collaborative school-based oral health program in a remote First Nations community," Rural and Remote Health, vol. 8, no. 2, p. 882, 2008.

[29] H. V. Worthington, K. B. Hill, J. Mooney, F. A. Hamilton, and A. S. Blinkhorn, "A cluster randomized controlled trial of a dental health education program for 10-year-old children," Journal of Public Health Dentistry, vol. 61, no. 1, pp. 22-27, 2001.

[30] W. H. van Palenstein Helderman, L. Munck, S. Mushendwa, M. A. van't Hof, and F. G. Mrema, "Effect evaluation of an oral health education programme in primary schools in Tanzania," Community Dentistry and Oral Epidemiology, vol. 25, no. 4, pp. 296-300, 1997.

[31] G. Bos, “The miswãk, an aspect of dental care in Islam," Medical History, vol. 37, no. 1, pp. 68-79, 1993.

[32] World Health Organization Expert Committee on Comprehensive School Health Education and Promotion, "Promoting health through schools," WHO Technical Report Series 870, 1997.

[33] D. Lister-Sharp, S. Chapman, S. Stewart-Brown, and A. Sowden, "Health promoting schools and health promotion in schools: two systematic reviews," Health Technology Assessment, vol. 3, no. 22, pp. 1-207, 1999.

[34] A. M. Moon, M. A. Mullee, L. Rogers, R. L. Thompson, V. Speller, and P. Roderick, "Helping schools to become healthpromoting environments-an evaluation of the Wessex Healthy Schools Award," Health Promotion International, vol. 14, no. 2, pp. 111-122, 1999. 
[35] I. Young, "Health promotion in schools-a historical perspective," Promotion \& Education, vol. 12, no. 3-4, pp. 112-117, 2005.

[36] S. Stewart-Brown, "What is the evidence on school health promotion in improving health or preventing disease and, specifically, what is the effectiveness of the health promoting schools approach?" WHO Regional Office for Europe, Copenhagen, Denmark (Health Evidence Network Report) 2006, http://www.euro.who.int/document/e88185.pdf.

[37] L. St Leger, I. Young, C. Blanchard, and M. Perry, "Promoting health in schools from evidence to action," http://www.dhhs.tas .gov.au/__data/assets/pdf_file/0007/117385/PHiSFromEvidenceToAction_WEB1.pdf.

[38] World Health Organization, "Nairobi Call to Action for Closing the Implementation Gap in Health Promotion," WHO, Geneva, Switzerland, 2009, http://javeriana.edu.co/redcups/Nairobi_ Call_for_Action.pdf.

[39] R. Langford, C. P. Bonnell, H. E. Jones et al., "The WHO health promoting school framework for improving the health and well-being of students and their academic achievement," The Cochrane Database of Systematic Reviews, no. 4, Article ID CD008958, 2014.

[40] M. Bardi, A. Burbank, W. Choi et al., "Activities for engaging schools in health promotion," Health Education, vol. 114, no. 4, pp. 271-280, 2014.

[41] J. Inchley, J. Muldoon, and C. Currie, "Becoming a health promoting school: evaluating the process of effective implementation in Scotland," Health Promotion International, vol. 22, no. 1, pp. 65-71, 2007.

[42] A. J. Macnab, F. A. Gagnon, and D. Stewart, "Health promoting schools: consensus, strategies, and potential," Health Education, vol. 114, no. 3, pp. 170-185, 2014.

[43] O. Samdal and L. Rowling, "Theoretical and empirical base for implementation components of health-promoting schools," Health Education, vol. 111, no. 5, pp. 367-390, 2011.

[44] A. J. Macnab, D. Stewart, and F. Gagnon, "Health promoting schools: initiatives in Africa," Health Education, vol. 114, no. 4, pp. 246-259, 2014.

[45] S. Dharamsi, R. Woollard, P. Kendal, I. Okullo, and A. J. Macnab, "Health promoting schools as learning sites for physicians intraining," Health Education, vol. 114, no. 3, pp. 186-196, 2014.

[46] A. MacNab and A. Kasangaki, “"Many voices, one song”: a model for an oral health programme as a first step in establishing a health promoting school," Health Promotion International, vol. 27, no. 1, pp. 63-73, 2012.

[47] S. Nörmark and H. J. Mosha, "Relationship between habits and dental health among rural Tanzanian children," Community Dentistry and Oral Epidemiology, vol. 17, no. 6, pp. 317-321, 1989.

[48] E. O. Sote, "The relative effectiveness of chewing sticks and toothbrush on plaque removal," African Dental Journal, vol. 1, no. 2, pp. 48-53, 1987.

[49] V. O. Rotimi and H. A. Mosadomi, "The effect of crude extracts of nine African chewing sticks on oral anaerobes," Journal of Medical Microbiology, vol. 23, no. 1, pp. 55-60, 1987.

[50] A. G. Jagtap and S. G. Karkera, "Extract of Juglandaceae regia inhibits growth, in-vitro adherence, acid production and aggregation of Streptococcus mutans," Journal of Pharmacy and Pharmacology, vol. 52, no. 2, pp. 235-242, 2000.

[51] J. J. Dietrich, J. Coetzee, K. Otwombe et al., "Adolescent-friendly technologies as potential adjuncts for health promotion," Health Education, vol. 114, no. 4, pp. 304-318, 2014.
[52] M. Quirynen, J. Dadamio, S. van den Velde et al., "Characteristics of 2000 patients who visited a halitosis clinic," Journal of Clinical Periodontology, vol. 36, no. 11, pp. 970-975, 2009.

[53] World Health Organization, Oral Health Surveys. Basic Methods, World Health Organization, Geneva, Switzerland, 3rd edition, 1987.

[54] L. M. Muwazi, C. M. Rwenyonyi, F. J. Tirwomwe et al., "Prevalence of oral diseases/conditions in Uganda," African Health Sciences, vol. 5, no. 3, pp. 227-233, 2005.

[55] M. Sparks, "The changing contexts of health promotion," Health Promotion International, vol. 28, no. 2, pp. 153-156, 2013.

[56] B. Hutchison, J.-F. Levesque, E. Strumpf, and N. Coyle, "Primary health care in Canada: systems in motion," Milbank Quarterly, vol. 89, no. 2, pp. 256-288, 2011.

[57] J. G. Kosteniuk, D. G. Morgan, J. Bracken, and P. Kessler, "Adventures in rural and remote health services innovation: the role of researcher as collaborator," Rural and Remote Health, vol. 14, article 2898, 2014.

[58] P. R. W. Kendall, C. Mangham, and D. W. Young, "An ounce of prevention," Paediatrics and Child Health, vol. 9, no. 3, pp. 151152, 2004.

[59] R. G. Davidson, S. Rustein, K. Johnson, E. Suliman, A. Wagstaff, and A. Amouzou, Socioeconomic Differences in Health, Nutrition, and Population within Developing Countries: An Overview, The World Bank, Washington, DC, USA, 2007.

[60] A. Wagstaff, "Poverty and health sector inequalities," Bulletin of the World Health Organization, vol. 80, no. 2, pp. 97-105, 2002.

[61] Y.-L. Lee, H.-Y. Hu, N. Huang, D.-K. Hwang, P. Chou, and D. Chu, "Dental prophylaxis and periodontal treatment are protective factors to ischemic stroke," Stroke, vol. 44, no. 4, pp. 1026-1030, 2013.

[62] J. C. N. Mbanya, A. A. Motala, E. Sobngwi, F. K. Assah, and S. T. Enoru, "Diabetes in sub-Saharan Africa," The Lancet, vol. 375, no. 9733, pp. 2254-2266, 2010. 


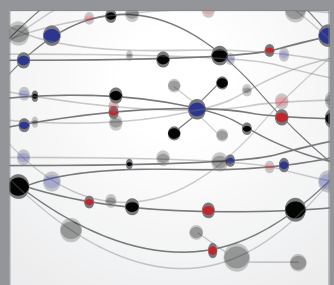

The Scientific World Journal
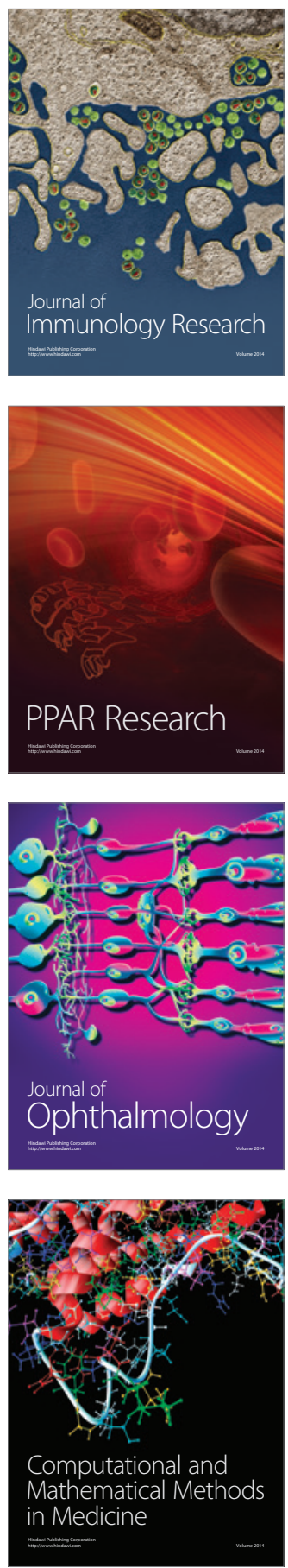

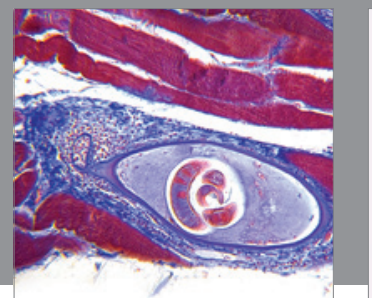

Gastroenterology

Research and Practice
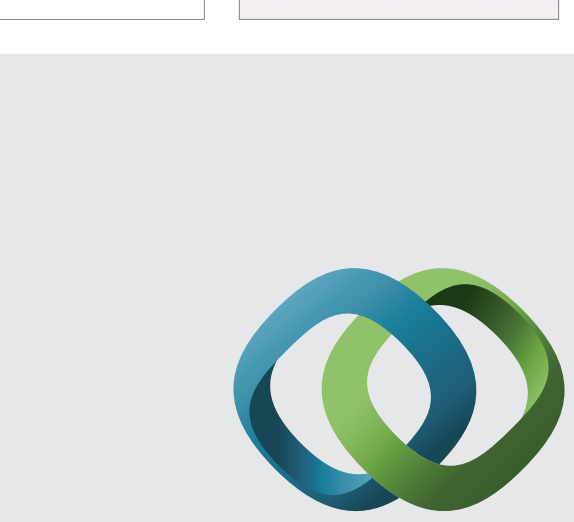

\section{Hindawi}

Submit your manuscripts at

http://www.hindawi.com
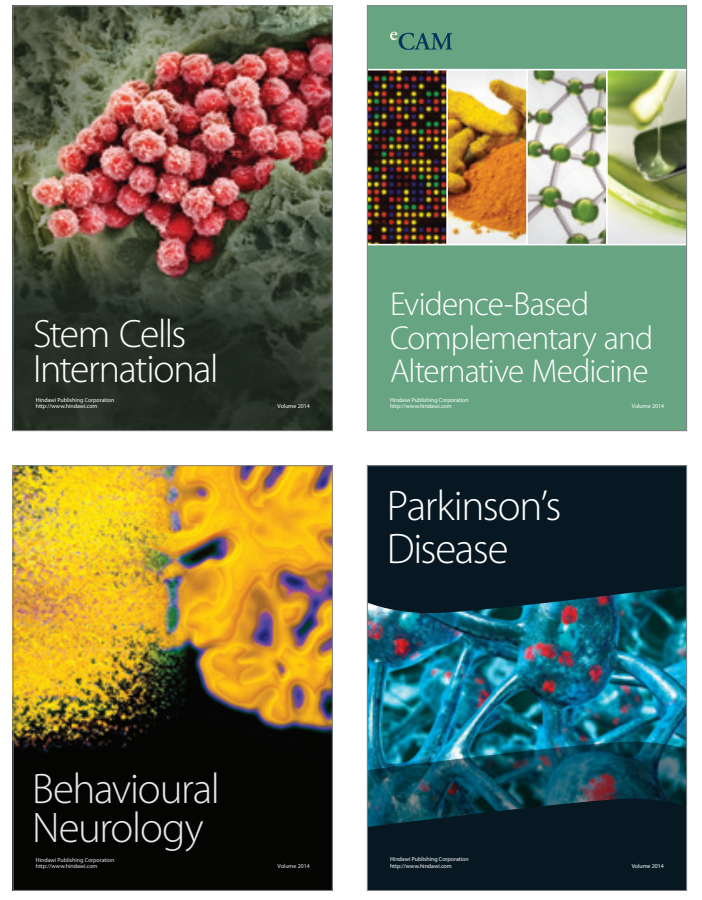
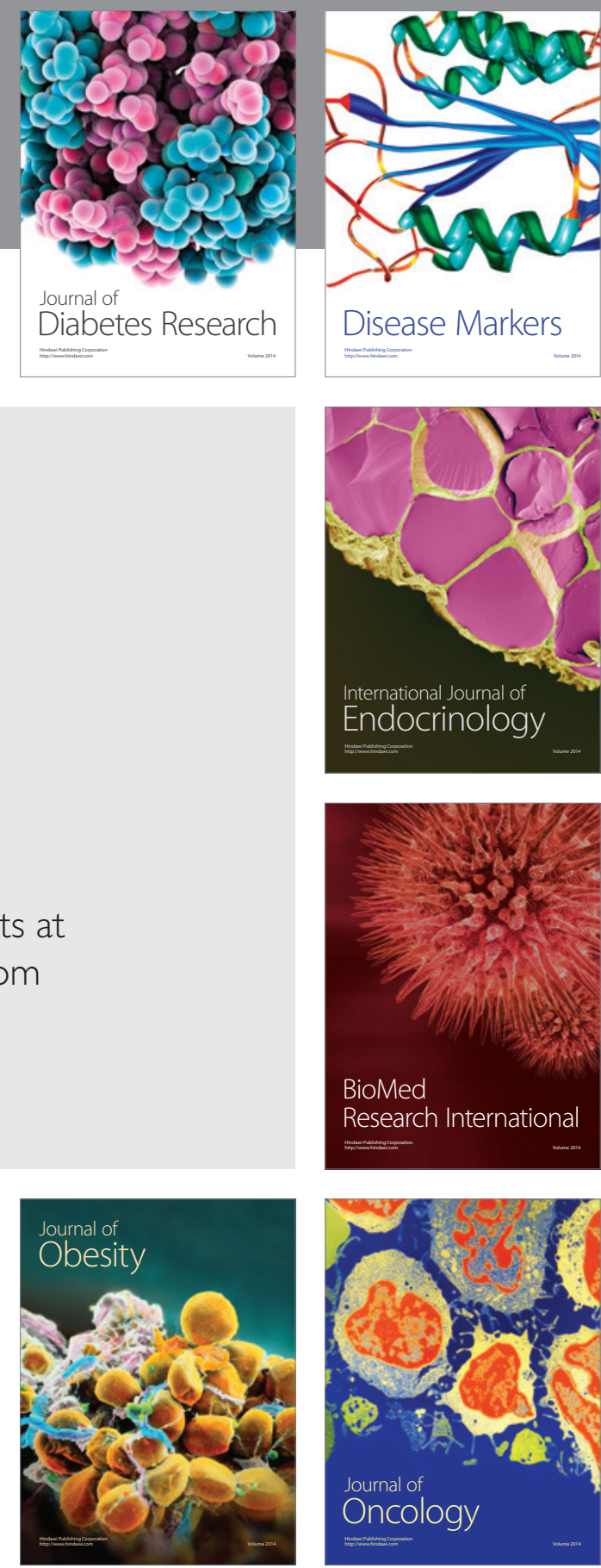

Disease Markers
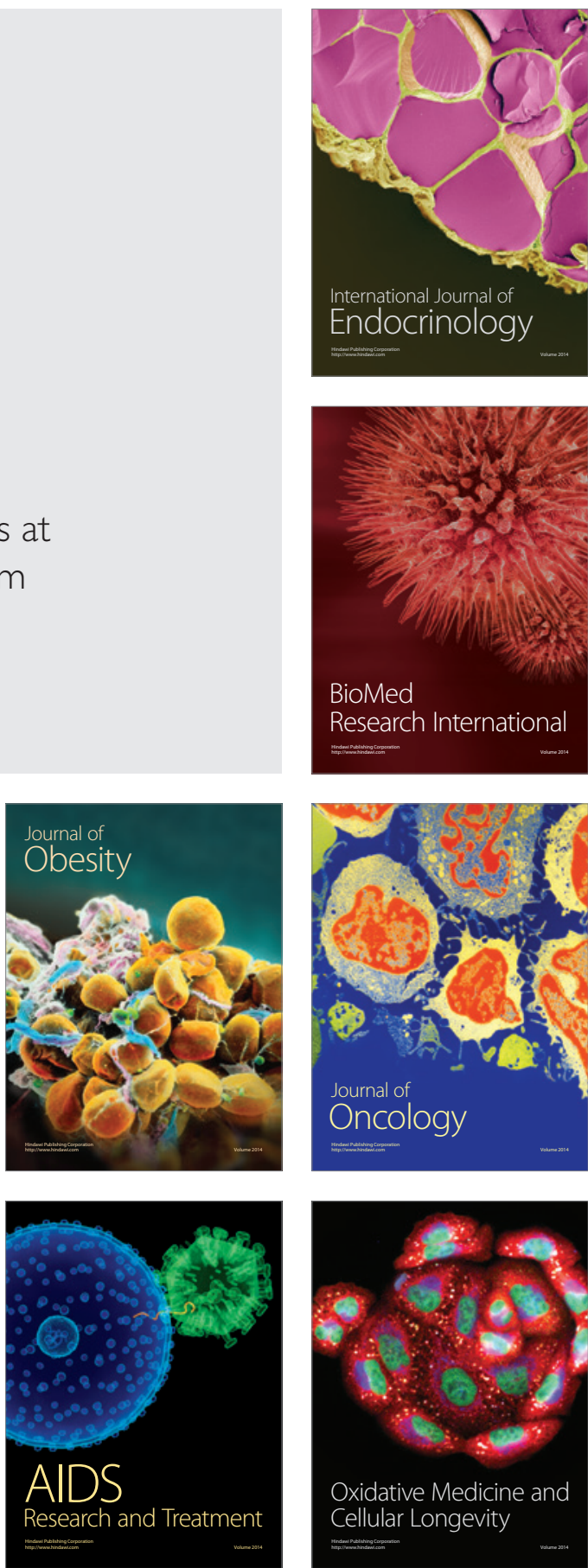